\title{
DIALOGYCA BDDH: REFLEXIONES METODOLÓGICAS ENTRE TRADICIÓN E INNOVACIÓN
}

\section{DIALOGYCA BDDH: METHODOLOGICAL REFLECTIONS AMONG TRADITION AND INNOVATION}

\author{
Eleonora Arrigoni \\ Universidad Complutense de Madrid \\ eleonorarrigoni@gmail.com
}

\begin{abstract}
Resumen
Dialogyca $B D D H$ es una base de datos especializada además de una biblioteca digital. Aspira a ofrecer de manera progresiva el corpus de todos los diálogos literarios hispánicos escritos en las distintas lenguas peninsulares desde el siglo XV hasta nuestros días. Se presentan los elementos metodológicos fundamentales de Dialogyca y se ofrecen tres ejemplos de obras descritas en la base de datos para demostrar que el método bibliográfico y la investigación literaria se benefician de las aplicaciones informáticas para mejorar la presentación de la información y obtener resultados novedosos. La colaboración entre instituciones y el enriquecimiento entre bases de datos permite la optimización de los recursos y la difusión de las informaciones.
\end{abstract}

Palabras clave: Dialogyca BDDH. Literatura hispánica. Diálogos. Base de datos. Biblioteca digital.

\section{Abstract}

Dialogyca $B D D H$ is a specialized data base in addition to a digital library. Aims to provide progressively the corpus of all Hispanic literary dialogues written in the different peninsular 
languages, from the fifteenth century until nowadays. Fundamental methodological elements of Dialogyca are presented and three examples of works described in the database are offered. They aim to demonstrate that the bibliographical method and literary research benefit from computer applications to improve the presentation of information and obtain new results. Collaboration between institutions and enrichment between databases allows the optimization of resources and the dissemination of information.

Keywords: Dialogyca BDDH. Hispanic Literature. Dialogues. Database. Digital Library.

\section{INTRODUCCIÓN}

Este trabajo surge a partir de una reflexión con relación a uno de los temas propuestos en el Segundo Congreso Internacional de Humanidades Digitales Hispánicas. Quiero aquí hacer una reflexión sobre la metodología de la investigación filológica y su relación con las herramientas informáticas y digitales. Para ello, recurro a la herramienta en cuya creación y alimentación he colaborado desde sus primeros pasos, como resultado de los trabajos del Grupo de Estudios de Prosa Hispánica Bajomedieval y Renacentista del Instituto Universitario Menéndez Pidal. Se trata de Dialogyca $B D D H$, acrónimo de Biblioteca Digital de Diálogo Hispánico o, simplemente, Dialogyca, por facilidad de difusión. Dialogyca lleva en acceso abierto desde 2010 y es posible acceder a varias intervenciones y presentaciones, en formato texto y vídeo, publicadas a través de nuestra web ${ }^{1}$.

\section{2. ¿QUÉ ES DIALOGYCA? ${ }^{2}$}

Para que sirva de marco de actuación, Dialogyca es una base de datos y biblioteca digital especializada. Ofrece la recopilación, análisis literario y bibliográfico de una colección de textos literarios acotados por el género dialógico de ámbito hispánico, desde sus orígenes, que remontan al siglo $\mathrm{XV}$, hasta la actualidad y acogiendo en consecuencia textos de características muy dispares en cuanto a temas tratados, época e idiomas. Los datos están presentados en forma de fichas en las que se incorpora también la reproducción digital completa de todos los testimonios que se consideran indispensables para establecer la correcta historia de la difusión del texto.

\footnotetext{
${ }^{1}$ Accesible desde http://www.dialogycabddh.es/.

2 Trabajo realizado en el marco del proyecto I+D FFI2012-33903/FILO.
} 
Precisamente porque cada ficha analítica es el resultado de la investigación exhaustiva sobre un diálogo no podemos hablar de Dialogyca simplemente como una biblioteca digital, sino más bien como una base de datos especializada y además biblioteca digital.

Remontándonos a los orígenes, la creación de la base de datos fue conformada en varias fases durante algunos años, primero en reuniones de todo el equipo de investigadores; más tarde en reuniones con los técnicos informáticos para que toda la casuística de los textos que conocíamos se encontrara plasmada en una estructura de campos acorde con ella. Recuerdo y cito esta primera fase porque fue, desde luego, un momento extremadamente creativo y de puesta en común, pero también de exigencia de síntesis de nuestros conocimientos y de claridad en nuestros objetivos. Entonces se tomaron las decisiones metodológicas que caracterizan a Dialogyca hoy y que, con la distancia del tiempo, han resultado ser un éxito por la fiabilidad con la que se pueden describir los textos, combinando la estructura codificada de los campos de la base de datos y la libertad de profundizar en los aspectos que cada investigador considera necesarios en su obra descriptiva. Considero que toda reflexión sobre metodología debe tener en consideración que el punto de partida necesario de nuestras investigaciones como filólogos, como bibliógrafos y como humanistas digitales siguen siendo inevitablemente los textos. Por mucho que la atención de la investigación se esté dirigiendo hacia los textos digitales, tenemos que seguir lidiando con esa doble naturaleza intrínseca al texto: la conceptual y la material. Con más razón cuando un texto ha sufrido cambios a lo largo de la historia de su transmisión textual: reconstruir cada paso de la transmisión misma es preciso para poder acercarnos a las palabras originarias del autor.

En este sentido, la metodología que aplicamos a nuestra base de datos, por un lado, la disciplina de la bibliografía y por otro, con la investigación literaria que nos sirve de marco y de objetivo a la vez. En nuestra investigación resulta imprescindible la aplicación del método bibliográfico sistematizado en la búsqueda, localización, identificación y descripción de los testimonios, tanto manuscritos como impresos de la obra en concreto que estamos analizando. En la díada filológico-bibliográfica, la aplicación informática es a la vez el medio con el que introducimos los datos y la funcionalidad que nos permite alcanzar la síntesis de nuestros resultados: un corpus de fichas relativas a cada obra dialógica con enlaces a digitalizaciones externas y a documentos PDF de elaboración propia, con opciones de búsqueda muy versátiles y la posibilidad de consulta online de acceso libre. Los recursos informáticos nos permiten agilizar procesos que anteriormente eran muy largos y a la vez reflejar con mayor precisión nuestra voluntad investigadora en la ficha. Por ejemplo, todas las búsquedas sencillas, por palabra clave o por campos, y las avanzadas, por términos admitidos o combinando campos, serían impensables con la exclusiva elaboración de los antiguos índices de los estudios en formato impreso. No por ello sugiero que debamos prescindir de 
todos los índices ya que los listados controlados siguen desempeñando una función fundamental en los procesos de revisión. De hecho, en un apartado de la portada de nuestra página web se puede encontrar publicado el índice por autor y título de todas las obras publicadas en Dialogyca hasta la fecha actual que permite conocer sin búsquedas intermedias lo que la base de datos ofrece.

Por otro lado, si la estructura de base de la ficha refleja la realidad de los textos y determina los elementos identificativos fundamentales de la obra (tales como el autor y el título en primer lugar), en el futuro podremos ampliar la información que se ofrece profundizando paulatinamente en los aspectos propios de cada texto. Por ejemplo, a través de documentos adjuntos -que no solo nuestra base admite, sino que además permite realizar búsquedas en el texto allí incluido- o incluso contiene enlaces a fichas de otras bases de datos (hasta ahora se trata de fichas catalográficas de opacs, pero nada impide que en futuro sean fichas de otras bases de datos especializadas).

Dialogyca se estructura alrededor del concepto de obra y no de testimonio o ejemplar. Por mucho que pueda resultar una cuestión obvia, no lo es en absoluto porque implica labores de recopilación selectiva y concordancia de aquellos testimonios concernientes a la transmisión de cada obra, dispersos en opacs y bibliotecas de todo el mundo.

\section{REDACCIÓN DE LAS FICHAS}

El proceso de redacción se estructura en varios pasos concatenados, sucesivos y muy controlados. Cada ficha describe el diálogo con los datos sobre sus autores, el título en todas sus variantes, sus características literarias y sus testimonios, además de ofrecer la bibliografía secundaria actualizada. Todas estas informaciones se sacan en primer lugar de los textos mismos, las fuentes primarias. Después de que nuestros colaboradores elijan el título de la obra sobre la que desean preparar la ficha, es preciso seleccionar cuáles son los testimonios de los que tendremos que ofrecer la digitalización. Solemos ofrecer la reproducción digital completa de todos los manuscritos y la editio princeps de la obra, además de todas las digitalizaciones ya disponibles online en otros repositorios y de todos aquellos que se consideran indispensables para establecer la correcta difusión del texto, añadiendo también enlace a todos aquellos que ya se encuentran digitalizados por las instituciones bibliotecarias que los conservan.

Entonces, nos dirigimos a la biblioteca que conserva el testimonio original para obtener su autorización de reproducción íntegra. Para ello hemos llegado ya a establecer convenios con 30 bibliotecas o instituciones a nivel internacional (que también están citadas y se pueden 
consultar en nuestra web) ${ }^{3}$. La labor de coordinación de los convenios o permisos es una de las que más esfuerzo ha requerido, pero es totalmente necesaria ya que no disponemos de testimonios propios. Hay una característica de nuestra base de datos que está relacionada con este aspecto: Dialogyca es de acceso abierto y libre pero el acceso a la visualización de los adjuntos (o sea la digitalización de los textos, la descripción del ejemplar digitalizado y la bibliografía secundaria) requiere el registro gratuito y la aceptación de las condiciones de consulta con fines de docencia e investigación, para salvaguardar precisamente los acuerdos de difusión firmados con las bibliotecas.

El siguiente paso es realizar el análisis de la obra para sistematizar en los campos de la base la información literaria que ofrecemos y llevar a cabo la descripción del testimonio a texto completo. Esto último puede hacerlo el investigador responsable de la ficha o un colaborador de Dialogyca y en cada caso el nombre del responsable aparecerá en el documento. Finalmente, se realiza la entrega de la ficha, la revisión por parte del equipo directivo, la carga centralizada de datos y el alta en una de nuestras citas semestrales periódicas.

Admito que el objetivo que nos hemos propuesto es ambicioso y que las fichas que realizamos requieren un esfuerzo notable, ya que pueden considerarse en sí mismas una publicación especializada sobre el estado de la cuestión de cada obra, a modo de compendios actualizados de todo los que se sabe sobre ese diálogo en la actualidad. Los resultados ya alcanzados incorporando textos importantes para la historia de la literatura y ofreciendo de forma constante información original nos indican que vamos por el camino adecuado. Esto es posible solo contando con colaboradores especializados y seleccionados específicamente para elaborar cada una de las fichas. De hecho, cada ficha no es sólo una recopilación de datos, sino más bien una investigación en todo su conjunto. La redacción de la ficha implica a menudo la investigación de aspectos inéditos en artículos independientes o sintetiza incluso toda la investigación de tesis doctorales realizadas en el marco del proyecto.

\section{TRES EJEMPLOS DE DIALOGYCA}

\subsection{Diálogo de la dignidad del hombre}

Quiero ahora presentar tres fichas redactadas en Dialogyca para que sirvan de ejemplo de la estructura y del alcance de la base de datos.

Una de las primeras fichas incorporadas a Dialogyca fue el Diálogo de la dignidad del hombre de Hernán Pérez de Oliva, elaborada por Consolación Baranda Leturio ${ }^{4}$. Entre los varios diálogos que escribió el que fuera rector de la Universidad de Salamanca, este, en

\footnotetext{
${ }^{3}$ Accesible desde http://www.dialogycabddh.es/instituciones-colaboradoras.

${ }^{4}$ BDDH6. Accesible desde http://iump.ucm.es/dialogycaBDDH/BDDH6/dialogo-de-la-dignidad-del-hombre.
} 
concreto, tiene una difusión muy interesante en cuanto que no se publicó de forma autónoma sino dentro de dos libros distintos junto con otras obras, tanto dialógicas como no dialógicas. Se quedó inédita a la muerte del autor y en las ediciones realizadas posteriormente por Francisco Cervantes de Salazar y Ambrosio de Morales, sobrino del autor, la obra se trata de forma muy diferente.

Gracias a la bibliografía primaria y secundaria disponemos en la ficha de todo el material necesario para elaborar la edición crítica del texto.

En las obras de Cervantes de Salazar el Diálogo de la dignidad del hombre está publicado junto con otras dos obras no dialógicas, mientras que las de Ambrosio de Morales incluyen otro diálogo y otras 12 obras no dialógicas. Se difundió en 4 ediciones de época, desde 1546 hasta 1787, y también hubo 4 traducciones de época del italiano al francés de la versión de Cervantes de Salazar (desde 1563 hasta 1642). Igualmente, también tenemos ediciones modernas en las que el Diálogo de la dignidad del hombre está publicado en forma autónoma desde 1873 hasta 1995, fecha de la última edición de la editorial Cátedra.

Los dos volúmenes recopilatorios incluyen varias obras, pero sólo el Diálogo de la dignidad del hombre es común a las dos. La única forma para expresar las relaciones entre ellos es generar tres fichas y utilizando el diálogo mismo para relacionarlas. En cambio, si hubiéramos creado sólo una ficha, la de nuestra obra, y hubiéramos citado exclusivamente la secuencia de páginas que incluye el texto de cada uno de los volúmenes de conjunto, habríamos afirmado de forma implícita que éstos eran en realidad volúmenes facticios. No es el caso ya que detrás de la reunión de las obras de cada uno de estos existe una explícita voluntad del editor literario. O sea, no están juntas casualmente así que no se puede prescindir de esta realidad formal que es a la vez sustancial. Ambas colectáneas (asíllamamos, de forma técnica, al conjunto misceláneo de obras dialogadas y no dialogadas, que pueden ser de un mismo o de diferentes autores) son fichas autónomas en Dialogyca y tienen un número identificativo de ficha propio. 


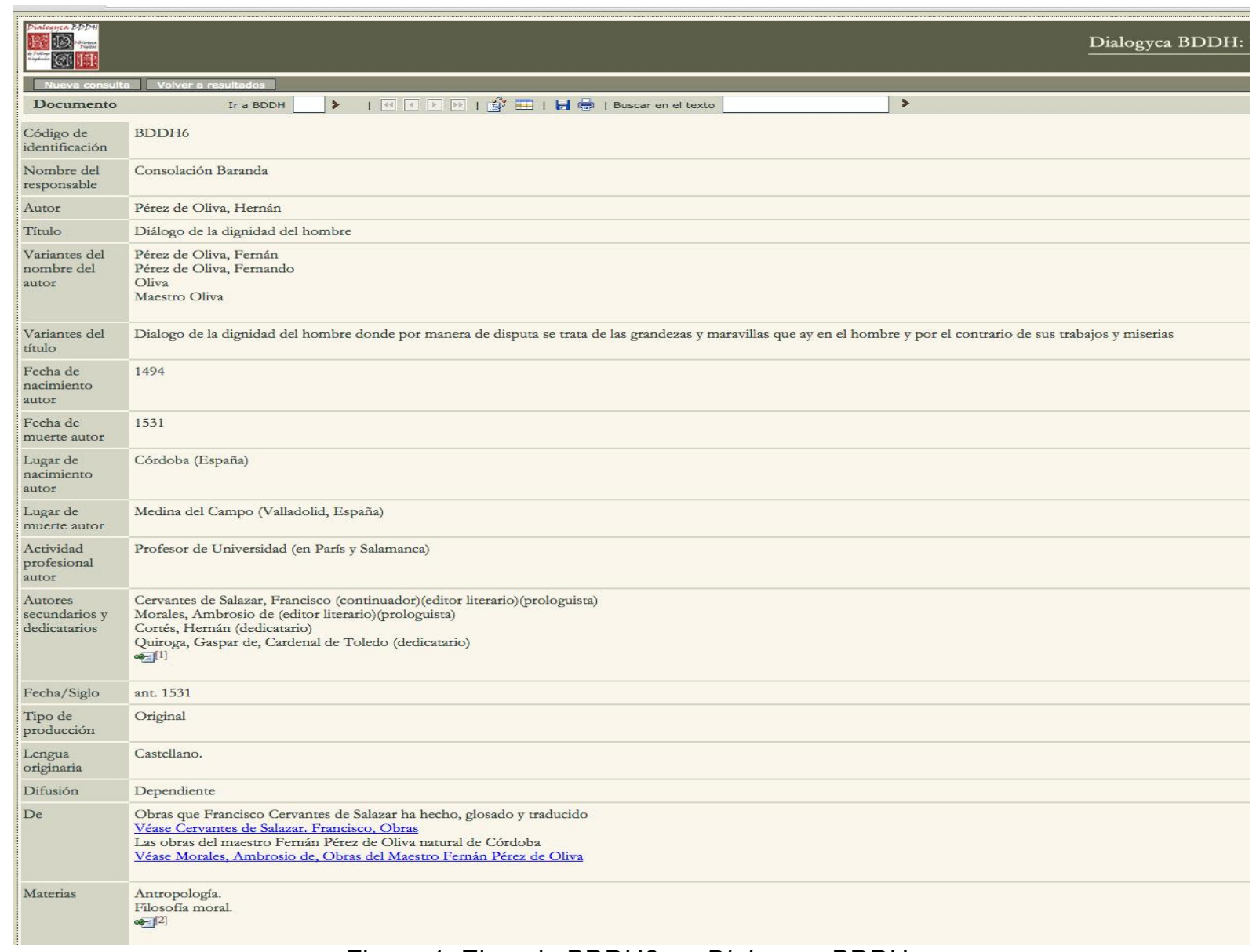

Figura 1. Ejemplo BDDH6 en Dialogyca BDDH.

Quisiera hacer hincapié en el concepto de número identificativo de cada ficha, o mejor dicho el código de identificación de Dialogyca. Fue quizás el primer punto firme de la base de datos y va más allá de ser un campo autonumérico necesario para que la base de datos simplemente identifique las fichas. Este campo, que es y tiene que ser visible al público, sirve también para citar cada ficha de forma unívoca, precedido de la sigla BDDH, ya que el equipo de Dialogyca asume la responsabilidad de que cada número se asocie a uno y sólo a un diálogo. En el caso de que con el tiempo nos diéramos cuenta de que un diálogo es en realidad parte de otro y no merece la autonomía descriptiva, por ejemplo, el código de identificación se quedaría vacío y, al buscarlo, aparecería una explicación de que ya no existe. El código de identificación asume en este contexto el valor que tiene la entrada o asiento de las bibliografías y que coincide con la identidad conceptual de una obra descrita. 


\subsection{Viaje de Turquía}

El segundo caso que quiero presentar describe el famoso diálogo titulado Viaje de Turquía ${ }^{5}$. Se trata de una descripción especial ya que Juan Miguel Valero Moreno, el autor de la ficha, está realizando también la edición crítica de este mismo texto para la colección de clásicos de la Real Academia Española. Aquí ofrece todo el material disponible para fijar el texto y lo hace con el mismo rigor de la edición impresa.

Es una obra que definimos exenta, o sea con difusión autónoma, muy elaborada: se conservan 5 manuscritos de época, 9 ediciones modernas y 7 traducciones modernas a otros idiomas. La política de Dialogyca es incluir los datos de todos los testimonios conocidos del diálogo ordenados cronológicamente y ofrecer los principales datos que conforman la noticia sintética del testimonio para su correcta identificación. En el caso de los manuscritos se ofrecen: autor, título, datación, signatura de la copia, descripción codicológica y digitalización del manuscrito. En el caso de los testimonios impresos: autor, título, datos de publicación y, en el caso de aportar también la digitalización completa, la signatura del ejemplar digitalizado y la descripción tipobibliográfica.

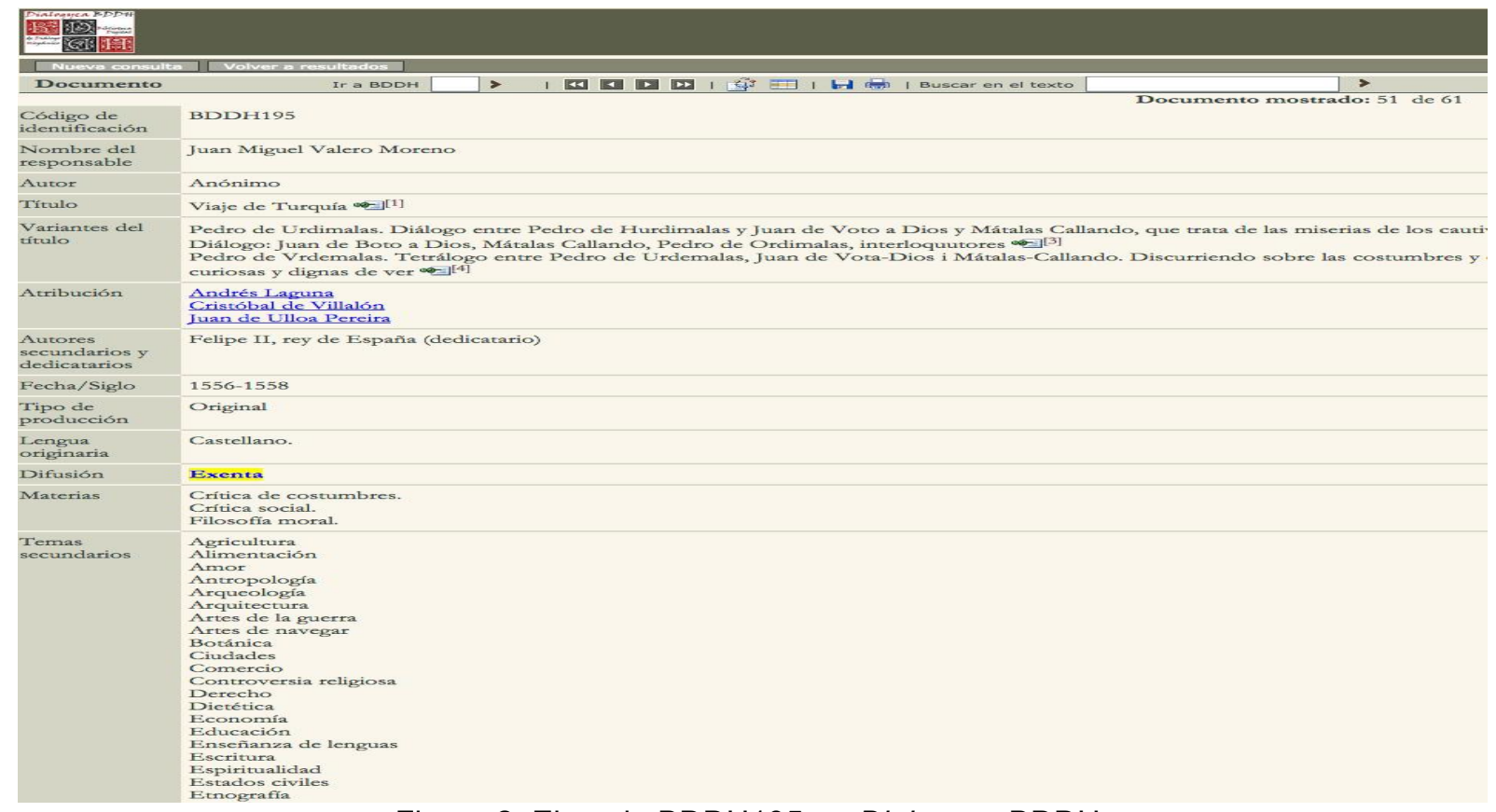

Figura 2. Ejemplo BDDH195 en Dialogyca BDDH.

\footnotetext{
${ }^{5}$ BDDH195. Accesible desde http://iump.ucm.es/dialogycaBDDH/BDDH195/viaje-de-turquia/.
} 


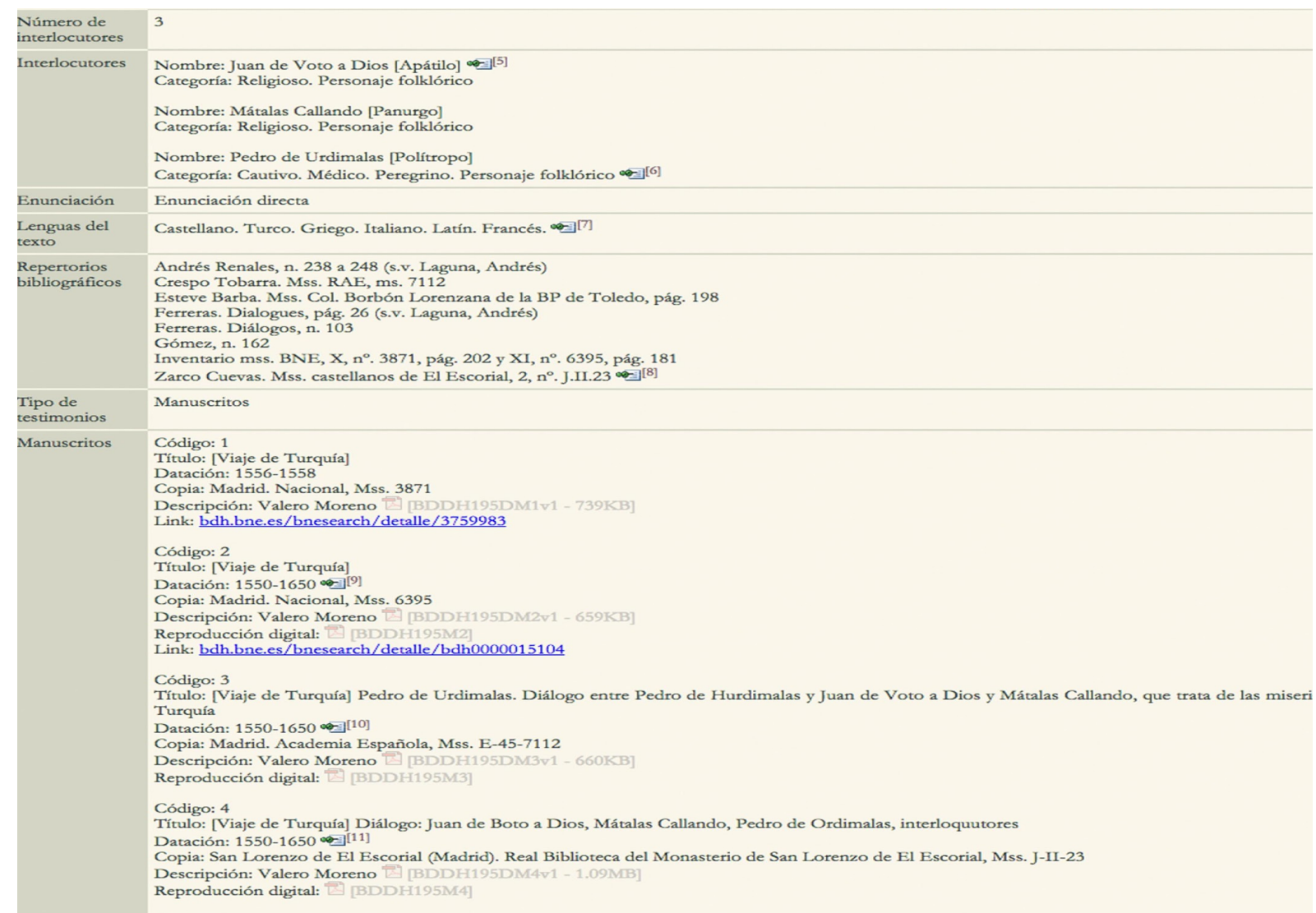

Figura 3. Ejemplo BDDH195 en Dialogyca BDDH.

Mediante el tratamiento bibliográfico de las fuentes primarias, asentaremos las bases del estudio de su contenido textual. Por ello, ofrecemos la descripción codicológica de todos los testimonios manuscritos y la tipobibliográfíca de la editio princeps y de aquellas ediciones posteriores que sean relevantes en la transmisión del texto. Las pautas codicológicas y tipobibliográficas para realizar las descripciones de los testimonios, como todas las demás informaciones sobre cómo rellenar los campos de las fichas, se encuentran explicadas en el Manual de Procedimiento de Trabajo Normalizado (Ilamado también PTN) en su versión extensa o resumida, que están disponibles a texto completo alojadas en eprints, el repositorio institucional de la Universidad Complutense de Madrid y accesibles por enlace desde la misma web de Dialogyca en el apartado Documentos y guías de trabajo ${ }^{6}$.

Las descripciones codicológicas y tipobibliográficas tienen la gran virtud de describir de forma analítica a cada manuscrito o edición impresa y en ellas se apoya el tratamiento de las reproducciones digitales que ofrecemos en formato PDF, pues los marcadores que incorporamos para podernos mover de forma más fluida dentro de los textos corresponden a esas descripciones.

\footnotetext{
${ }^{6}$ Accesible desde http://www.dialogycabddh.es/documentos-y-guias-de-trabajo.
} 


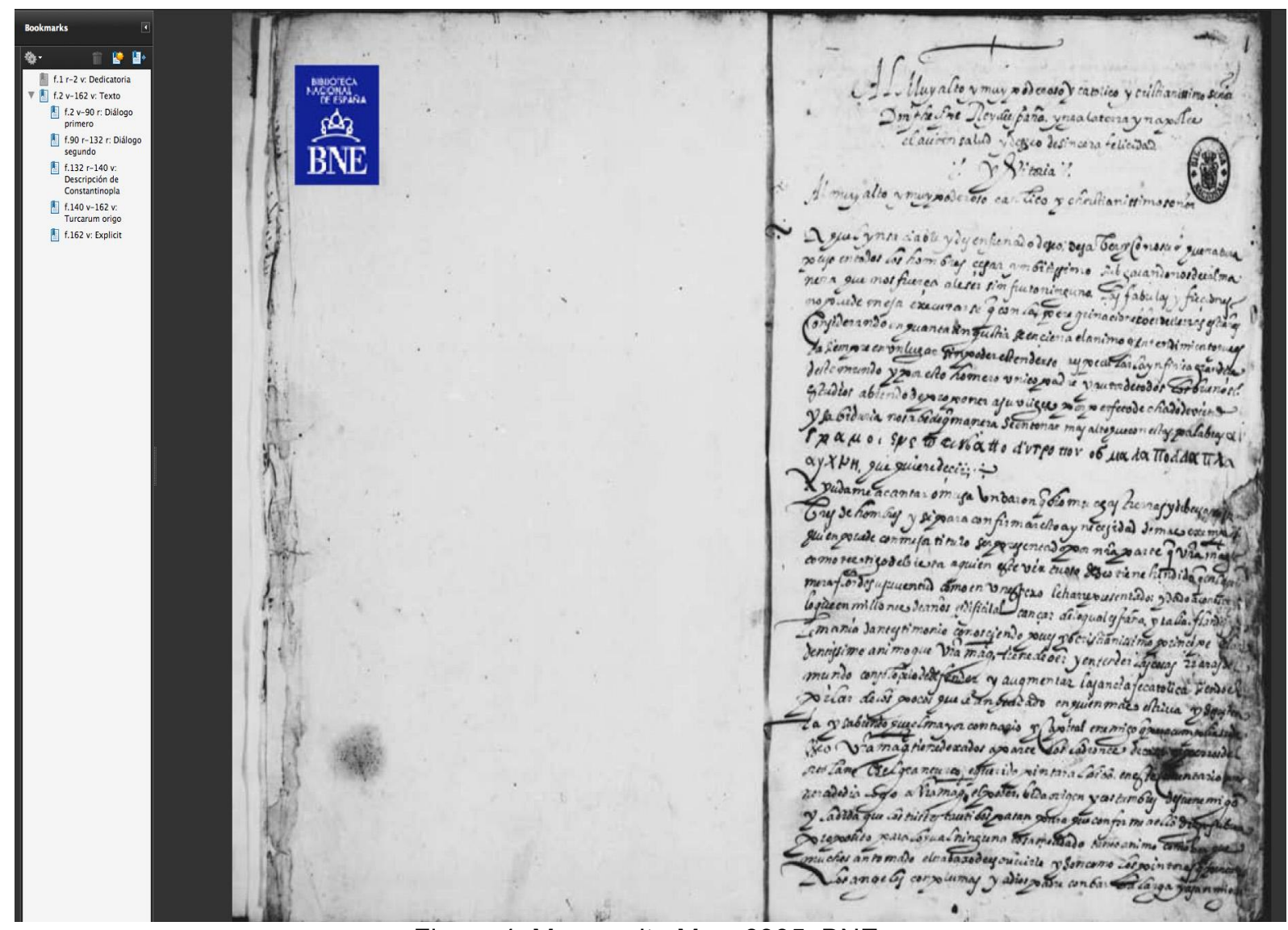

Figura 4. Manuscrito Mss. 6395, BNE.

En este diálogo tenemos los tres tipos de reproducciones completas que se pueden encontrar en nuestras fichas: enlaces a recursos externos, como es el caso del manuscrito 1, Mss. 3871 de la Biblioteca Nacional de España reproducido en su Biblioteca Digital Hispánica, con la que enlazamos; digitalizaciones en formato PDF proporcionadas al proyecto por otras entidades, como es el caso de la digitalización del manuscrito 5 (Mss. 259 de la Biblioteca de Castilla La Mancha) y del 3 (Mss. E-45-7112 de la Real Academia Española); y digitalizaciones en formato PDF realizadas por nosotros mismos a partir de reproducciones en microfilm o fotocopias de las que disponemos en el archivo Dialogyca, gracias a anteriores proyectos de investigación financiados con fondos públicos, como es el caso de la digitalización del manuscrito 2 (Mss. 6395 de la Biblioteca Nacional de España).

El Viaje de Turquía resulta especialmente interesante porque ofrece la ocasión de hablar de un reciente logro de Dialogyca en su relación con la Biblioteca Nacional de España. Me refiero al enlace desde la ficha descriptiva del opac de la Biblioteca Nacional de los manuscritos con signatura Mss. 6395 y Mss. 3871 a la ficha de Dialogyca. Este caso pone de manifiesto cómo sí es posible lograr la colaboración y el enriquecimiento recíproco entre recursos digitales cuando éstos ofrecen estabilidad, solidez metodológica y confianza en los contenidos. 


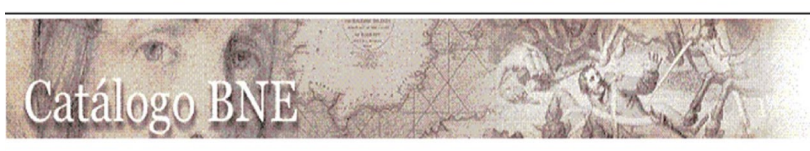

VOLVER AYUdA NUEVA BÚSOUEDA HaCIA ATRÁS HACIA DELANTE CAMBIAR VISUALZZACIÓN GUARDADOS TERMINAR

Inicio Colecciones especiales Autoridades Bibliografía Española Recursos electrónicos

registro 1 de 9 para la búsqueda "Viaje de Turquía"
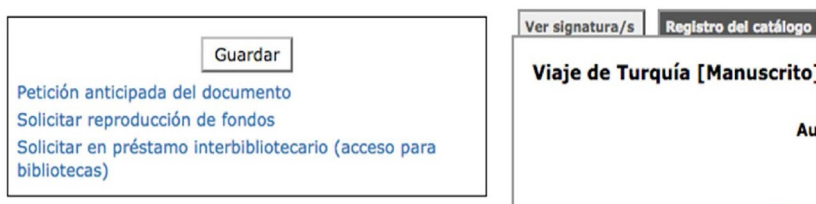

Viaje de Turquía [Manuscrito]

Cambiar visualización

Autor personal Villalón, Cristóbal de (ca. 1505-ca. 1581)

Título Viaje de Turquía [Manuscrito]

Publicación , S. XVII

Descripción física II, 162 h. ; $30 \times 22 \mathrm{~cm}$

Nota general V.a. Mss/3871

Nota de procedencia Conde de Gondomar

Enlace Biblioteca Digital Hispánica

Enlace Dialogyca: Biblioteca Digital del Diálogo Hispánico

Enlace Inventario General de Manuscritos

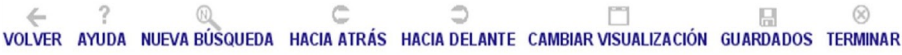

Figura 5. Ficha descriptiva del opac de la Biblioteca Nacional de los manuscritos con signatura Mss.

6395 y Mss. 3871 a la ficha de Dialogyca.

Se trata del resultado de varios años de colaboración que se concretaron en un convenio institucional entre la Universidad Complutense y la Biblioteca Nacional con el fin de optimizar los recursos de investigación por un lado y de digitalización de los materiales por otro $^{7}$. Entiendo que este tipo de acciones dan valor al trabajo que se realiza y permiten la difusión de la información elaborada para un público más amplio.

Entre las ediciones modernas, la 2 y la 7 (que corresponden a la edición de Antonio García Solalinde de 1919 y a la de Fernando García Salinero de 1980, respectivamente) se recogen enlaces externos de la digitalización realizada por la Biblioteca Virtual Cervantes ${ }^{8}$.

Disponemos además de un sistema de notas con enlaces internos que funciona de forma similar a las notaciones tradicionales, pero al pinchar sobre el número de la nota es posible moverse automáticamente al punto correspondiente de la nota o del texto de la ficha. Consideramos que las notas, dentro de las cuales también funciona la búsqueda por texto libre, permiten detallar la información y garantizan la libertad intelectual del investigador, ya que aquí puede reunir todas aquellas aclaraciones o matizaciones que considera muy relevantes y que no encuentran cabida en el sistema rígido de los campos.

\footnotetext{
${ }^{7}$ Accesible desde http://www.bne.es/es/LaBNE/Cooperacion/Cooperacion/nternacional/Colaboraciones.

${ }^{8}$ Accesible desde http://www.cervantesvirtual.com.
} 


\subsection{Coloquios en Eco}

El tercer ejemplo que quiero proponer es relativo a la colección de autoría múltiple Ciertos ecos a manera de coloquios entre ciertas personas y el sonido de sus voces que se dice eco, compuesta entre 1550 y $1580^{\circ}$.Se trata de una colección porque incluye varios textos dialógicos, en concreto ocho, que se difundieron juntos en el manuscrito 9175 de la Biblioteca Nacional de España que se describió y digitalizó en Dialogyca. Desde la ficha de colección se enlaza entonces a otras 8 fichas, una por cada uno de los diálogos individuales, en las que se recogen los datos y características propias de cada uno de los textos.

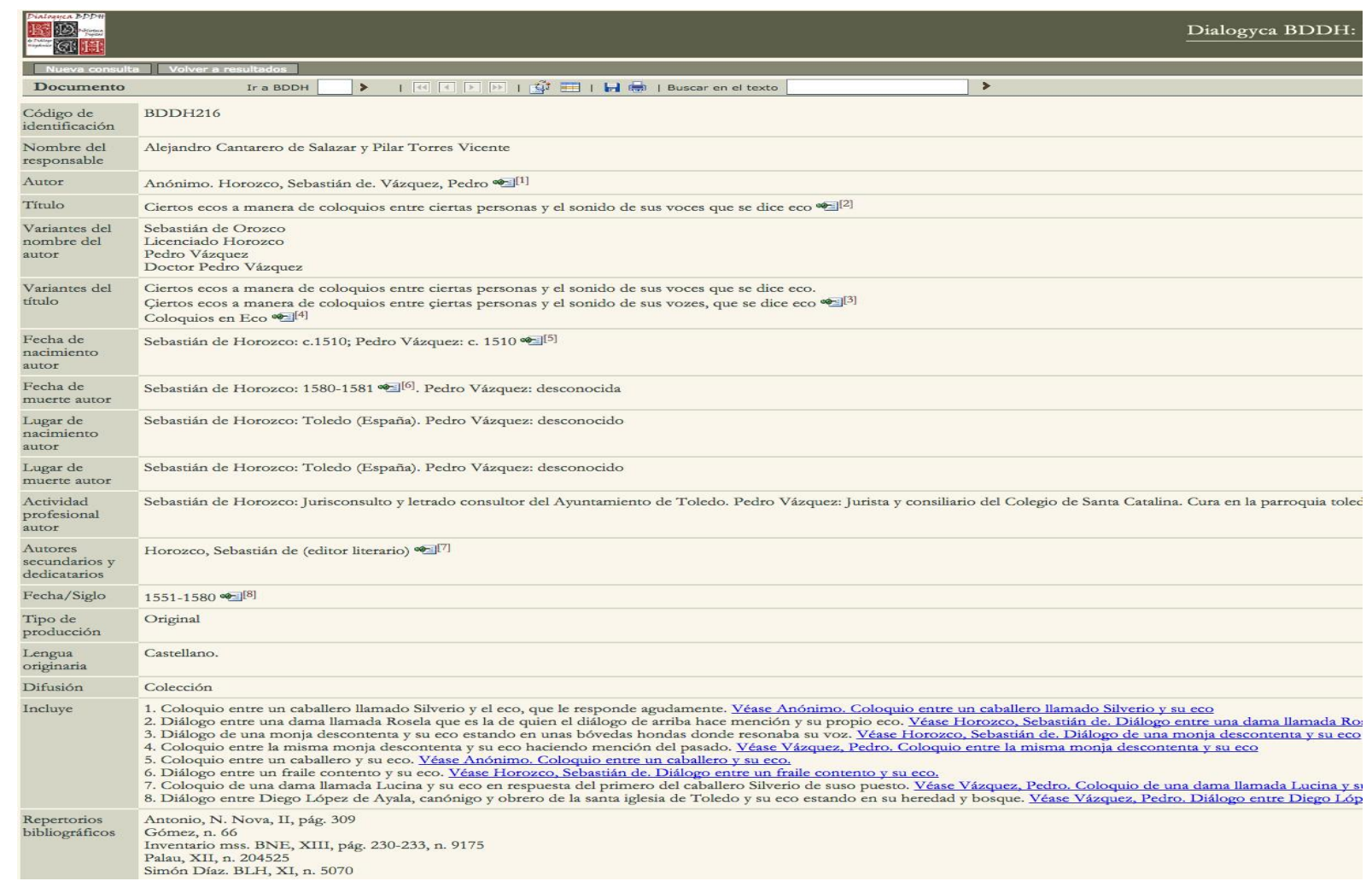

Figura 6. BDDH216 en Dialogyca BDDH.

\section{CONCLUSIONES}

Volviendo a la reflexión inicial, considero que, en el caso de Dialogyca, la innovación consiste en poder ver finalizado con éxito en una única pantalla y con un resultado sintético, completo y revisado, los que son los pasos iniciales y necesarios para la edición crítica de un texto, el acercamiento a su comprensión y lectura.

\footnotetext{
${ }^{9}$ BDDH216. Accesible desde http://iump.ucm.es/dialogycaBDDH/BDDH216/ciertos-ecos-a-manera-de-coloquiosentre-ciertas-personas-y-el-sonido-de-sus-voces-que-se-dice-eco.
} 
El conjunto de textos que prevemos reunir es muy extenso, ya que se trata de un género que goza de enorme éxito durante el siglo XVI, pero abarca, en realidad, un período desde la Edad Media hasta nuestros días, y la redacción de las fichas supone una investigación exhaustiva. De hecho, ya disponemos de 248 fichas en la base de datos ${ }^{10}$ y empieza a ser posible realizar búsquedas cruzadas para estudios o reflexiones monográficas sobre el género.

Algunos jóvenes investigadores de nuestro grupo de investigación ya presentaron en 2014 un análisis sobre las traducciones en los diálogos y, en el mes de noviembre de 2015, en el marco de la XV Semana de la Ciencia, hablamos de los diálogos de materia científica. Queda de manifiesto la utilidad prioritaria (y acertada, en nuestro caso) de ser muy rigurosos en la indicación de las materias y temas secundarios de los que se trata en los textos. Temas tales como Astronomía, Política, Crítica de costumbres, o Sucesos particulares, nos permiten extraer una visión directa de los intereses de diferentes autores por los problemas de su época. La multidisciplinariedad de los diálogos reside, desde luego, en su contenido pero también en el tipo de destinatarios cuyo interés pueden llegar a despertar por las finalidades más variadas. En otra vertiente, la clasificación pormenorizada de todos los interlocutores y sus categorías permite realizar categorizaciones concretas sobre la tipología de los mismos: tenemos animales, personajes históricos, arquetipos, figuras alegóricas, personajes mitológicos e, incluso, siglos ${ }^{11}$.

El impacto de Dialogyca en las investigaciones recientes es cada vez mayor. Lo comprobamos por las estadísticas de acceso y de suscripción a la base de datos. Desde luego, seguimos contactando con expertos para la redacción de las fichas y, a la vez, nos estamos moviendo para ampliar la difusión de nuestros resultados entre especialistas y no especialistas. Por ello, estamos optimizando nuestra página web (disponible desde marzo de 2016) junto con la nueva creación de un Boletín de novedades. Sugiero a todos los interesados subscribirse al acceso completo de Dialogyca y navegar en ella.

\footnotetext{
${ }^{10}$ Accesible desde http://www.dialogycabddh.es/wp-content/uploads/Autores-y-obras.pdf.

${ }^{11}$ BDDH229. Accesible desde http://iump.ucm.es/dialogycaBDDH/BDDH229/el-dialogo-de-los-siglos.
} 